\title{
Menthol/cyclodextrin inclusion complex nanofibers: Enhanced water- solubility and high-temperature stability of menthol
}

\author{
Zehra Irem Yildiz, Asli Celebioglu, Mehmet Emin Kilic, Engin Durgun, Tamer Uyar* \\ Institute of Materials Science \& Nanotechnology, UNAM-National Nanotechnology Research Center, Bilkent University, Ankara 06800, Turkey
}

\section{A R T I C L E I N F O}

\section{Article history:}

Received 7 November 2017

Received in revised form

20 December 2017

Accepted 21 December 2017

Available online 27 December 2017

\section{Keywords:}

Cyclodextrins

Electrospinning

Menthol

Fast-dissolving

Water-solubility

High-temperature stability

\begin{abstract}
A B S T R A C T
Cyclodextrins are capable of forming non-covalent host-guest inclusion complexation with variety of molecules in order to enhance water-solubility and thermal stability of such hydrophobic and volatile molecules. Menthol, an efficient antibacterial and flavour/fragrance agent, is used in various applications like food, pharmacy, cosmetics, however, its low water-solubility and high volatility somewhat limit its application. In this study, menthol/cyclodextrin-inclusion complex (menthol/CD-IC) was formed in highly concentrated aqueous solution by using hydroxypropyl- $\beta$-cyclodextrin (HP $\beta C D$ ) and hydroxypropyl- $\gamma$-cyclodextrin ( $\mathrm{HP} \gamma \mathrm{CD}$ ). The phase solubility studies and computational modeling studies revealed that menthol and these two CDs (HP $\beta C D$ and $H P \gamma C D)$ formed stable inclusion complexes with the optimal molar ratio of 1:1 (menthol:CD) and inclusion complex formation enhanced the watersolubility of menthol. The electrospinning of nanofibers (NFs) from highly concentrated aqueous solutions $(160 \%, w / v)$ of menthol/CD-IC was successfully performed without using additional fiber forming polymer and bead-free and uniform menthol/CD-IC NFs in the form of self-standing and flexible nanofibrous webs were produced. The initial molar ratio $(1: 1$, menthol:CD) of the menthol/CD-IC in the solutions was mostly preserved in the menthol/CD-IC NFs (above 0.70:1.00, menthol:CD). The watersolubility of menthol was enhanced and menthol/CD-IC NFs have shown fast-dissolving character. The slow-release of menthol was achieved for menthol/CD-IC NFs, and the evaporation of menthol was shifted to much higher temperature (up to $275^{\circ} \mathrm{C}$ ) for menthol/CD-IC NFs which proved the hightemperature stability for menthol due to inclusion complexation.
\end{abstract}

() 2017 Elsevier Ltd. All rights reserved.

\section{Introduction}

Cyclodextrins (CDs) are natural compounds produced from enzymatic conversion of starch (Szejtli, 1998). CDs are cyclic oligosaccharides composed of $\alpha-(1,4)$ linked glucopyranose units with truncated cone shape that allows inclusion complex (IC) formation with guest molecules. The cavity of this cone is favorable for hydrophobic compounds due to its relatively hydrophobic nature while the outer part of the cone has hydrophilic nature which increases water-solubility of guest molecules (Del Valle, 2004; Hedges, 1998). The most common native CDs are named as $\alpha-C D$, $\beta-C D$ and $\gamma-C D$ which have six, seven and eight glucopyranose units, respectively. However, aqueous solubility of native CDs are relatively low, therefore; to increase their water solubility and extend their applications, CDs can be chemically modified by

\footnotetext{
* Corresponding author.

E-mail address: tamer@unam.bilkent.edu.tr (T. Uyar).
}

substituting some of the hydroxyl groups with hydroxypropyl group located on the primary and/or secondary face of the molecule (Del Valle, 2004; Hedges, 1998; Szejtli, 1998). Molecular encapsulation approach with CDs is often applied in order to extend the shelf-life and prevent the loss of flavour/fragrance compounds during storage and processing (Marques, 2010). Once they are molecularly encapsulated with CDs, this reduces or eliminates any losses of flavour/fragrance compounds through evaporation and this also provides higher water-solubility for such hydrophobic compounds. Hence, CDs are quite applicable starchbased natural and non-toxic materials to form molecular encapsulation with essential oils and flavour/fragrance compounds used in food, pharmaceutics and cosmetic industries, etc.

Menthol ((1R,2S,5R)-2-isopropyl-5-methylcyclohexanol) is a flavor/fragrance compound which is naturally occurring, volatile, cyclic terpene alcohol (Galeotti et al., 2002). It is found in plants of Mentha species and gives them the typical minty smell and flavor. It has used in many fields like pharmacy, food, cosmetics, pesticides 
etc. (Galeotti et al., 2002; Patel et al., 2007). Menthol is a highly volatile compound and it has a very low soluble in water, so, these drawbacks sometimes limit the use of menthol in certain applications (Ades et al., 2012; Phunpee et al., 2016). Formation of cyclodextrin inclusion complex (CD-IC) with menthol prevents the loss of menthol during storage and processing (Liu et al., 2000), and this will also provide higher water solubility for menthol (Buschmann and Schollmeyer, 2002). There are recent studies including encapsulation of menthol by CDs to improve properties of menthol. In one of those studies, inclusion complex of menthol with hydroxypropyl- $\beta$-cyclodextrin (HP $\beta C D$ ) in powder form was produced (Zhu et al., 2016) and the thermal stability enhancement of menthol was shown. In another recent study, $\beta-C D$ grafted chitosan was used for entrapment of menthol molecules to analyze release profile of menthol (Phunpee et al., 2016).

Electrospinning is one of the most effective techniques for producing functional nanofibers and nanofibrous materials due to its versatility and being a cost-effective technique. Electrospun nanofibers have high surface area to volume ratio, nanoporous structure, light-weight and design flexibility which lead to their use in various areas such as biotechnology, membranes/filters, food, active food packaging, agriculture, textiles, composites, sensors and energy (Aytac et al., 2017a; Noruzi, 2016; Sahay et al., 2012; Uyar and Kny, 2017). Electrospinning of nanofibers from polymer solutions is very common since entanglements and overlapping, which are provided by polymers with high molecular weight or high concentration, play crucial role for proper nanofiber production (Ramakrishna, 2005; Shenoy et al., 2005; Theron et al., 2004). In other words, electrospinning of nanofibers from non-polymeric systems and small molecules is always a challenge without using any fiber forming carrier polymeric matrix. In our previous studies, by means of the electrospinning technique, CD-ICs of menthol by using natural CD types $(\alpha-C D, \beta-C D$ and $\gamma-C D)$ were formed and then they were encapsulated in electrospun polymeric nanofiber matrix to develop functional nanofibrous materials. The electrospun polymeric nanofibers encapsulating menthol/CD-IC have shown enhanced durability and thermal stability of menthol due to CD-IC formation (Uyar et al., 2009a, 2011, 2009b). Yet, the polymeric nanofiber matrices used were synthetic polymers such as polystyrene (Uyar et al., 2009a), polyethylene oxide (Uyar et al., 2011) and poly (methyl methacrylate) (Uyar et al., 2009b) which were not preferable for food applications, in addition, the amount of loaded menthol $(5 \%, w / w$ or less) in these fiber matrix was limited. In our recent studies, pure CDs have been successfully electrospun into uniform nanofibers in the form of nanofibrous webs without using polymers (Celebioglu and Uyar, 2012, 2013). Moreover, our previous studies have shown that the electrospinning of nanofibers from CD-IC systems was also possible (Aytac et al., 2016a, 2016b, 2017b; Celebioglu et al., 2014, 2016; Celebioglu and Uyar, 2011, 2017). Although, the weight \% of the loaded active agents was around $5 \%, \mathrm{w} / \mathrm{w}$ or less for electrospun polymeric nanofibers, the electrospinning of polymer-free CD-IC systems allowed us to accomplish a much higher weight loading (10-15\%, $\mathrm{w} / \mathrm{w}$ ) of active agents in the pure CD-IC fiber matrix (Aytac et al., 2016a, 2016b; Celebioglu et al., 2016). More importantly, these pure CD-IC nanofibrous materials can be edible and more suitable for food applications since they are just composed of CDs and food additives. In the present study, highly concentrated aqueous solutions $(160 \%, w / v)$ of menthol/CD-IC were prepared with two different CDs; hydroxypropyl- $\beta$-cyclodextrin (HP $\beta C D)$ and hydroxypropyl- $\gamma$-cyclodextrin (HP $\gamma C D$ ), with $1: 1 \mathrm{M}$ ratio (menthol:CD). Then, electrospinning of nanofibers (NFs) these two menthol/CD-IC systems (menthol/HP $\beta C D-I C$ NFs and menthol/ $\mathrm{HP} \gamma \mathrm{CD}-\mathrm{IC}$ NFs) was successfully performed in order to obtain selfstanding nanofibrous webs (Fig. 1). The water-solubility, thermal stability and the release of menthol from menthol/CD-IC NFs was investigated.

\section{Materials and methods}

\subsection{Materials}

The hydroxypropyl- $\beta$-cyclodextrin (HP $\beta C D$, Cavasol ${ }^{\circledR} \mathrm{W} 7 \mathrm{HP}$ Pharma) and hydroxypropyl- $\gamma$-cyclodextrin ( $\mathrm{HP} \gamma \mathrm{CD}$, Cavasol ${ }^{\mathbb{R}} \mathrm{W} 8$ HP) were given as free-samples for research purpose by Wacker Chemie AG (Germany). Menthol (>99\%, Sigma-Aldrich), deuterated dimethylsulfoxide (DMSO-d6, Merck) potassium bromide $(\mathrm{KBr}$, FTIR grade, Sigma-Aldrich) were purchased. All the materials were used as-received without any further purification process. The deionized water used in this study was obtained from Millipore Milli-Q ultrapure water system.

\subsection{Preparation of electrospinning solutions}

CDs can form aggregates via intermolecular hydrogen bonding in their highly concentrated solutions and therefore, electrospinning of nanofibers is possible from such highly concentrated CD solutions without the need of any fiber forming polymeric matrix (Celebioglu and Uyar, 2012). In our previous study (Celebioglu and Uyar, 2012), bead-free and uniform CD nanofibers were electrospun from the optimized concentration $(160 \%(\mathrm{w} / \mathrm{v})$ of CD with respect to solution) of modified CDs (HP $\beta C D$ and HP $\gamma C D)$ in water. Therefore, in this study, the same optimized concentration of $\mathrm{CD}$ was used to form menthol/CD-IC solutions for the electrospinning. For the preparation of menthol/CD-IC aqueous solutions, firstly, menthol was dispersed in water, then, $\operatorname{HP} \beta C D(160 \%, w / v)$ and $\mathrm{HP}_{\gamma} \mathrm{CD}(160 \%, \mathrm{w} / \mathrm{v})$ were separately added to these aqueous menthol dispersion systems. The amount of $\mathrm{CD}$ and menthol was adjusted in order to get $1: 1 \mathrm{M}$ ratio of menthol/HP $\beta C D-I C$ and menthol/HP $\gamma$ CD-IC. These suspensions were stirred overnight at room temperature. To minimize the loss of menthol during stirring, the glass vial $(5 \mathrm{~mL})$ was sealed tightly. At the end, the aqueous solutions of menthol/HP $\beta C D-I C$ and menthol/HP $\gamma$ CD-IC were obtained for the electrospinning (Fig. 1a). For comparison, pure $C D$ solutions (HP $\beta C D$ and $\mathrm{HP} \gamma \mathrm{CD}$ ) at a concentration of $160 \%(\mathrm{w} / \mathrm{v})$ were prepared in water for the electrospinning.

\subsection{Electrospinning of nanofibers}

Each solution of CD (HP $\beta C D$ and HP $\gamma C D)$ and menthol/CD-ICs (menthol/HP $\beta C D-I C$ and menthol/HP $\gamma$ CD-IC) was loaded into $1 \mathrm{~mL}$ syringe having a metallic needle (inner diameter $=0.4 \mathrm{~mm}$ ) separately. The syringe was placed horizontally on the syringe pump (KD Scientific, KDS 101). High voltage at $10-15 \mathrm{kV}$ was applied between tip of needle and the collector by the high voltage power supply (Spellman, SL Series). The distance between tip and collector was kept at $10-15 \mathrm{~cm}$. The feed rate of the solutions was varied between 0,5 and $1 \mathrm{~mL} / \mathrm{h}$. Electrospun nanofibrous webs were collected on the metal collector which was covered by aluminum foil. Electrospinning was performed at $25^{\circ} \mathrm{C}$ and $35 \%$ relative humidity. Pure CD nanofibers (HP $\beta C D$ NFs and HP $\gamma C D$ NFs) were electrospun for comparative studies with menthol/CD-IC NFs (menthol/HP $\beta C D-I C ~ N F s$ and menthol/HP $\gamma$ CD-IC NFs).

\subsection{Measurements and characterization}

Phase solubility diagram was obtained according to the method reported by Higuchi and Connors (1965). An excess amount of menthol was added to aqueous solutions of HP $\beta C D$ and HP $\gamma C D$ in capped vials which were shaken at room temperature in the dark 
for $48 \mathrm{~h}$. After $48 \mathrm{~h}$, solutions were filtered through a $0.45-\mu \mathrm{m}$ membrane filter to remove undissolved part and the dissolved concentration of menthol was spectrophotometrically (Varian, Cary $100)$ determined. The experiment was carried out in triplicate and average of three measurements was taken. The apparent stability constant $\left(\mathrm{K}_{\mathrm{s}}\right)$ of menthol/CD-IC was calculated from the phase solubility diagram according to the following equation:

$\mathrm{K}_{\mathrm{s}}=$ slope $/ \mathrm{S}_{0}$ (1-slope)

where $\mathrm{S}_{0}$ is the intrinsic solubility of menthol.

Computational method was also used to study the inclusion complexation between menthol and two types of CD (HP $\beta C D$ and $\mathrm{HP} \gamma(\mathrm{CD})$. The first-principles analysis depending on density functional theory (DFT) was performed (Hohenberg and Kohn, 1964; Kohn and Sham, 1965; Kresse and Furthmuller, 1996). The exchange-correlation functional was expressed by generalized gradient approximation (Perdew et al., 1996) including van der Waals correction (Grimme, 2006). All the elements were described by pseudopotentials generated by projector augmented-wave method (Blochl, 1994). The energy cutoff for plane wave basis set was chosen as $520 \mathrm{eV}$. The initial structures of host cyclodextrin, guest molecule (menthol) and their inclusion complexes were relaxed by minimizing the total energy and reducing the forces on atoms below $0.01 \mathrm{eV} / \mathrm{A}$. The Brillouin zone was sampled by single $\mathrm{k}-$ point at Gamma-point and supercell was generated such that there is at least $10 \AA$ between periodic images to avoid spurious interactions. The solvent effect was examined by implementing

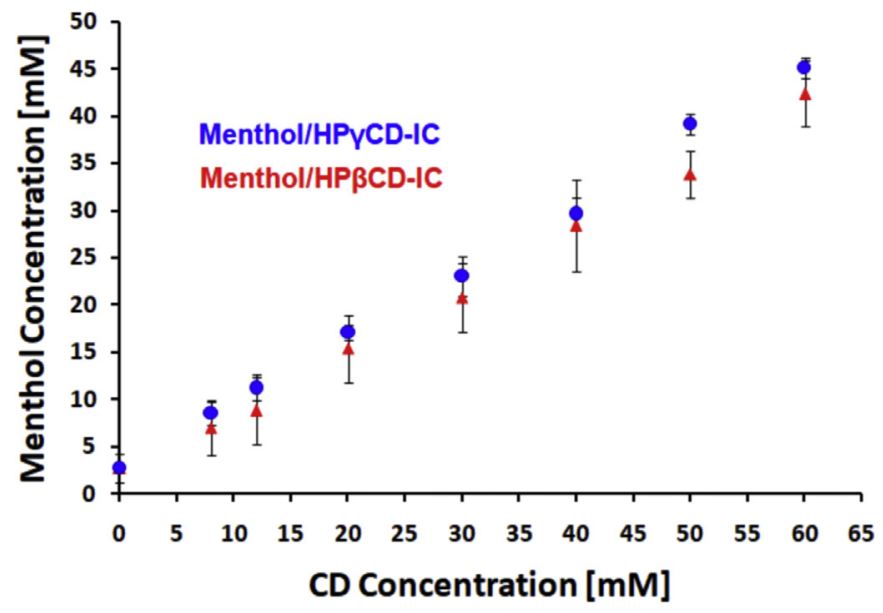

Fig. 2. Phase solubility diagrams of menthol/HP $\beta C D-I C$ and menthol/HP $\gamma C D-I C$, $(n=3)$.

implicit solvent method which uses continuum dielectric description to describe the solvent (Mathew et al., 2014). Complexation energy $\left(\mathrm{E}_{\mathrm{comp}}\right)$ of the resulting complexes can be computed by using the following formula:

$\mathrm{E}_{\mathrm{comp}}=\mathrm{E}_{\mathrm{CD}}+\mathrm{E}_{\text {menthol }}-\mathrm{E}_{\mathrm{IC}}$

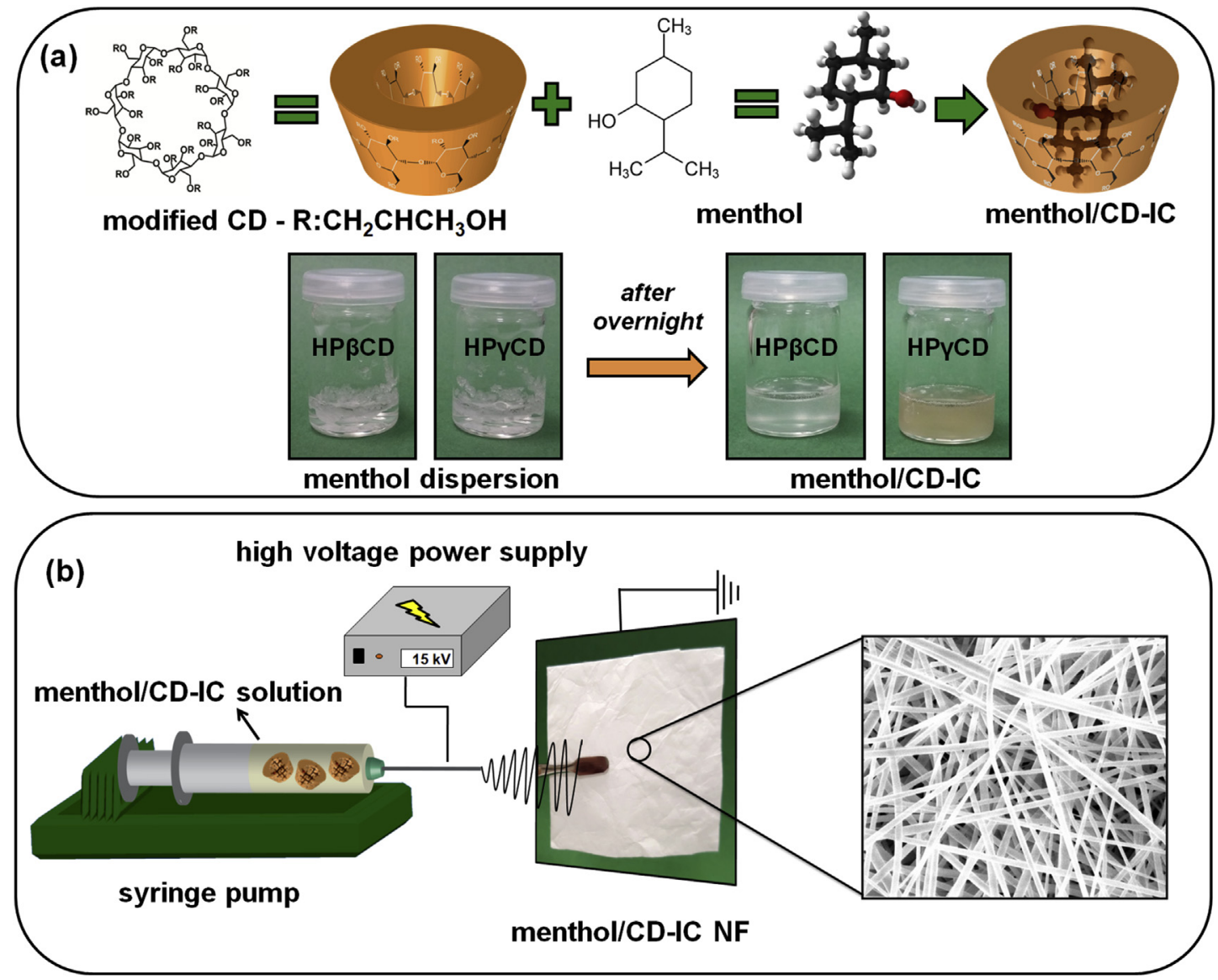

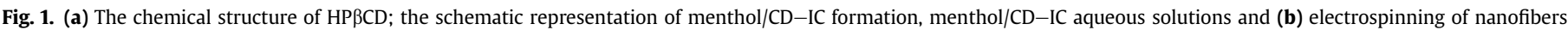
from menthol/CD-IC aqueous solution. 
where $E_{C D}, E_{\text {menthol }}$ and $E_{I C}$ is the total energy of host $C D$ molecule (HP $\beta C D$ or $\mathrm{HP} \gamma \mathrm{CD}$ ), the guest molecule (menthol), and their IC, respectively. The energies were calculated in vacuum and water separately considering 1:1 menthol:CD stoichiometry. The solvation energy $\left(E_{\text {solv }}\right)$ of the considered structures and their IC can be obtained by using calculated energies in vacuum and water by considering the formula below:

$\mathrm{E}_{\mathrm{solv}}=\mathrm{E}_{\mathrm{water}}-\mathrm{E}_{\mathrm{vacuum}}$

$E_{\text {water }}$ and $E_{\text {vacuum }}$ is the total energy of menthol, $C D$, or menthol/ CD-IC in water and vacuum, respectively.

A rheometer (Anton Paar, Physica CR 301) equipped with a cone/ plate accessory (spindle type $\mathrm{CP} 20-4$ ) was used to measure the rheological behavior of menthol/HP $\beta C D-I C$ and menthol/HP $\gamma C D-I C$ solutions at a constant shear rate of $100 \mathrm{~s}^{-1}$ at $25^{\circ} \mathrm{C}$. The conductivity of the solutions was measured by a Multiparameter InoLab ${ }^{\circledR}$ Multi 720-WTW at room temperature.

The morphological analyses of the electrospun nanofibers were performed by using scanning electron microscope (SEM) (FEI Quanta 200 FEG) (Aytac et al., 2016b). Samples were sputtered with $5 \mathrm{~nm} \mathrm{Au} / \mathrm{Pd}$ prior to SEM imaging by PECS-682 to minimize charging problem. The average fiber diameter (AFD) was determined from the SEM images, and around 100 fibers were analyzed for each sample.

The infrared spectra for pure menthol, pure CD NFs, and menthol/CD-IC NFs were obtained by using a Fourier transform infrared spectrometer (FTIR) (Bruker-VERTEX 70). For measurement, the samples were blended with $\mathrm{KBr}$ and pressed as pellets. The 64 scans were recorded between $4000 \mathrm{~cm}^{-1}$ and $400 \mathrm{~cm}^{-1}$ at resolution of $4 \mathrm{~cm}^{-1}$ (Celebioglu and Uyar, 2011). The X-ray diffraction (XRD) (PANalytical X'Pert powder diffractometer) data (a)

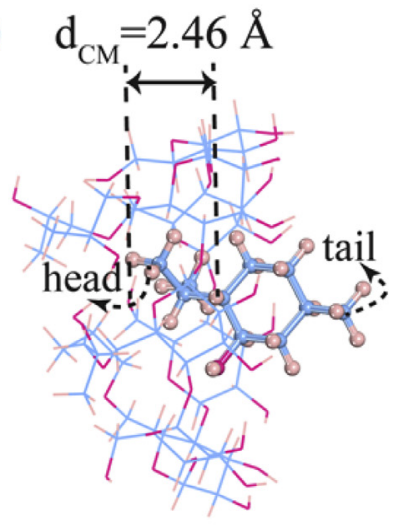

(b)

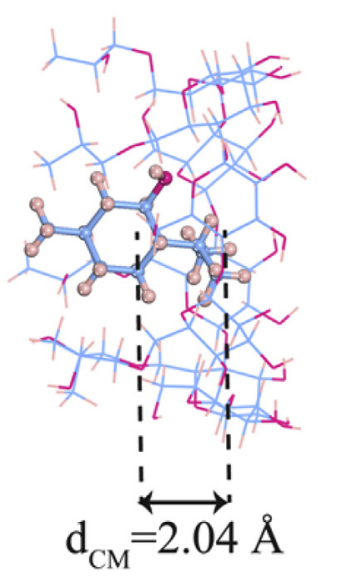

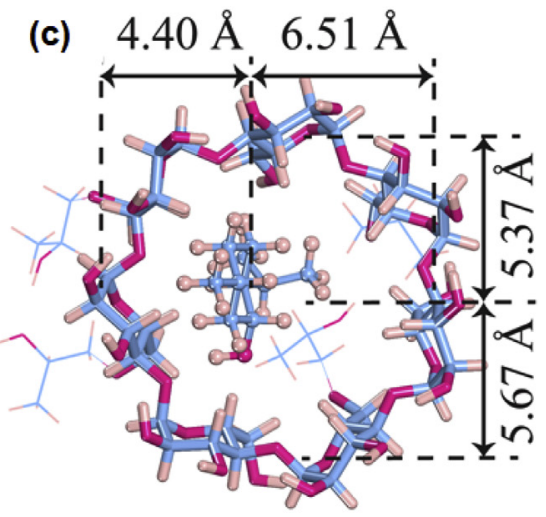

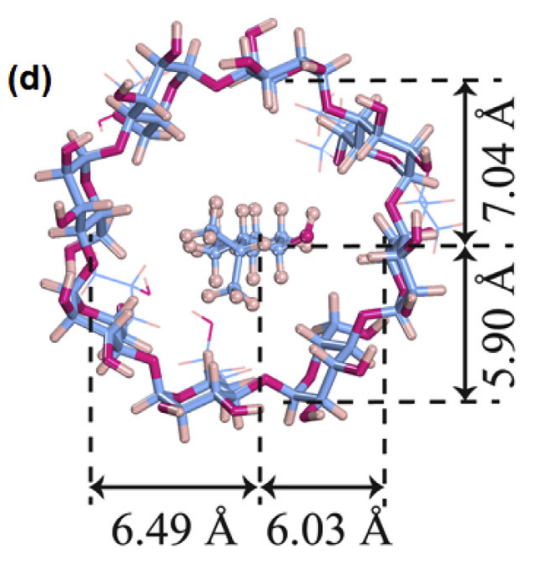

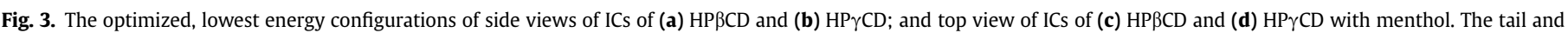

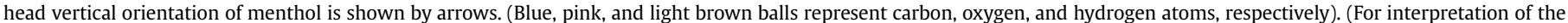
references to colour in this figure legend, the reader is referred to the Web version of this article.)

Table 1

Complexation and solvation energies of the menthol, CDs (HP $\beta C D$ and HP $\gamma C D)$ and menthol within CDs at different orientations.

\begin{tabular}{|c|c|c|c|c|c|}
\hline Host & Guest & Orientation & $\mathrm{E}_{\text {comp }}$ (vacuum) kcal/mol & $\mathrm{E}_{\text {comp }}$ (water) kcal/mol & $\mathrm{E}_{\text {solv }} \mathrm{kcal} / \mathrm{mol}$ \\
\hline $\mathrm{HP} \beta C D$ & - & - & - & - & -71.17 \\
\hline HP $\beta C D$ & Menthol & Head & 26.62 & 21.50 & -68.93 \\
\hline $\mathrm{HP} \beta C D$ & Menthol & Tail & 23.24 & - & - \\
\hline $\mathrm{HP} \beta C D$ & Menthol & Lateral & 21.25 & - & - \\
\hline $\mathrm{HP} \gamma \mathrm{CD}$ & - & - & - & - & -83.34 \\
\hline $\mathrm{HP} \gamma \mathrm{CD}$ & Menthol & Head & 19.23 & - & - \\
\hline $\mathrm{HP} \gamma \mathrm{CD}$ & Menthol & Tail & 23.71 & 16.72 & -79.23 \\
\hline $\mathrm{HP} \gamma \mathrm{CD}$ & Menthol & Lateral & 23.20 & - & - \\
\hline- & Menthol & - & - & - & -2.89 \\
\hline
\end{tabular}


of the pure menthol, pure CD NFs and menthol/CD-IC NFs were recorded by using $\mathrm{Cu} K \alpha$ radiation in a range of $2 \theta=5^{\circ}-30^{\circ}$ (Celebioglu and Uyar, 2011). The molar ratio of menthol to CD in menthol/CD-IC NFs was determined by using proton nuclear magnetic resonance $\left({ }^{1} \mathrm{H}\right.$ NMR, Bruker D PX-400) system. The menthol/CD-IC NFs were dissolved in DMSO-d6 at the $30 \mathrm{gl}^{-1}$ concentration. The spectra were recorded at $400 \mathrm{MHz}$ and at 16 total scan (Celebioglu et al., 2014). Thermogravimetric analyses (TGA, TA Q500, USA) were performed for pure menthol, pure CD NFs, and menthol/CD-IC NFs. The TGA were conducted under nitrogen atmosphere by heating the samples from $30^{\circ} \mathrm{C}$ to $600^{\circ} \mathrm{C}$ at the heating rate of $20^{\circ} \mathrm{C} / \mathrm{min}$.

Headspace gas chromatography-mass spectrometry (HS GC-MS, Agilent Technologies 7890A gas chromatograph equipped with 5975C mass spectrometer) was used to determine the amount of menthol released from menthol/HP $\beta C D-I C$ NF and menthol/ $\mathrm{HP} \gamma \mathrm{CD}-\mathrm{IC}$ NF for $150 \mathrm{~min}$. The release experiments were carried out in triplicate and the results were reported as average \pm standard deviation. The capillary column was HP-5MS (Hewlett-Packard, Avondale, PA) (30 m X $0.25 \mathrm{~mm}$ i.d., $0.25 \mathrm{~m}$ film thickness). A $10 \mathrm{mg}$ of menthol/HP $\beta C D-I C$ NF and menthol/HP $\gamma$ CD-IC NF was separately placed in $20 \mathrm{~mL}$ headspace glass vials which was agitated by $500 \mathrm{rpm}$ at $37{ }^{\circ} \mathrm{C}$ and $75^{\circ} \mathrm{C}$ (Aytac et al., 2016b). The syringe temperature was kept the same as the incubation temperature. The oven temperature was held at $60^{\circ} \mathrm{C}$ for $1 \mathrm{~min}$ and increased to $165^{\circ} \mathrm{C}$ at the rate of $10^{\circ} \mathrm{C} / \mathrm{min}$ and equilibrated at this temperature for $1 \mathrm{~min}$. Helium was used as a carrier gas at a flow rate of $1.2 \mathrm{~mL} /$

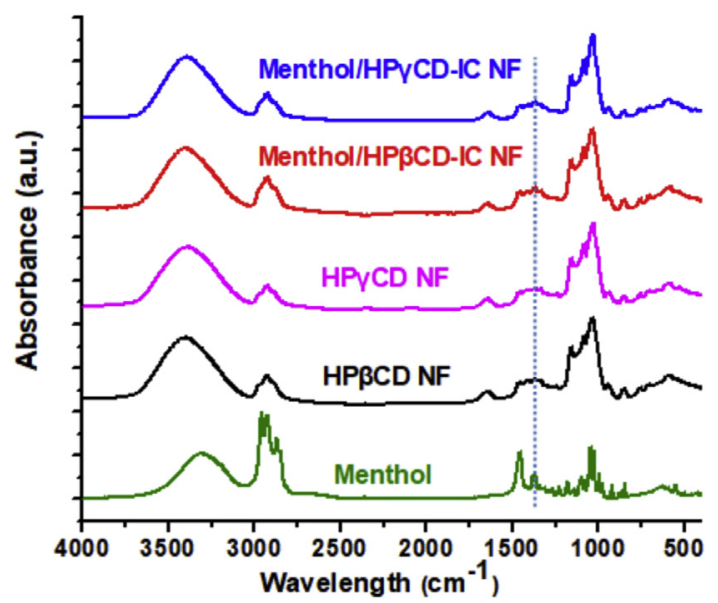

Fig. 5. FTIR spectra of pure menthol, pure CD NFs and menthol/CD-IC NFs.

min. The menthol peak was identified by comparing its mass spectrum with that of menthol in the Search 2.0 and NIST MS libraries.

The fast-dissolving character and water-solubility enhancement were studied visually by the addition of water directly to the pure menthol and menthol/CD-IC NFs samples. The video (see supporting information) and photos were taken in which, menthol
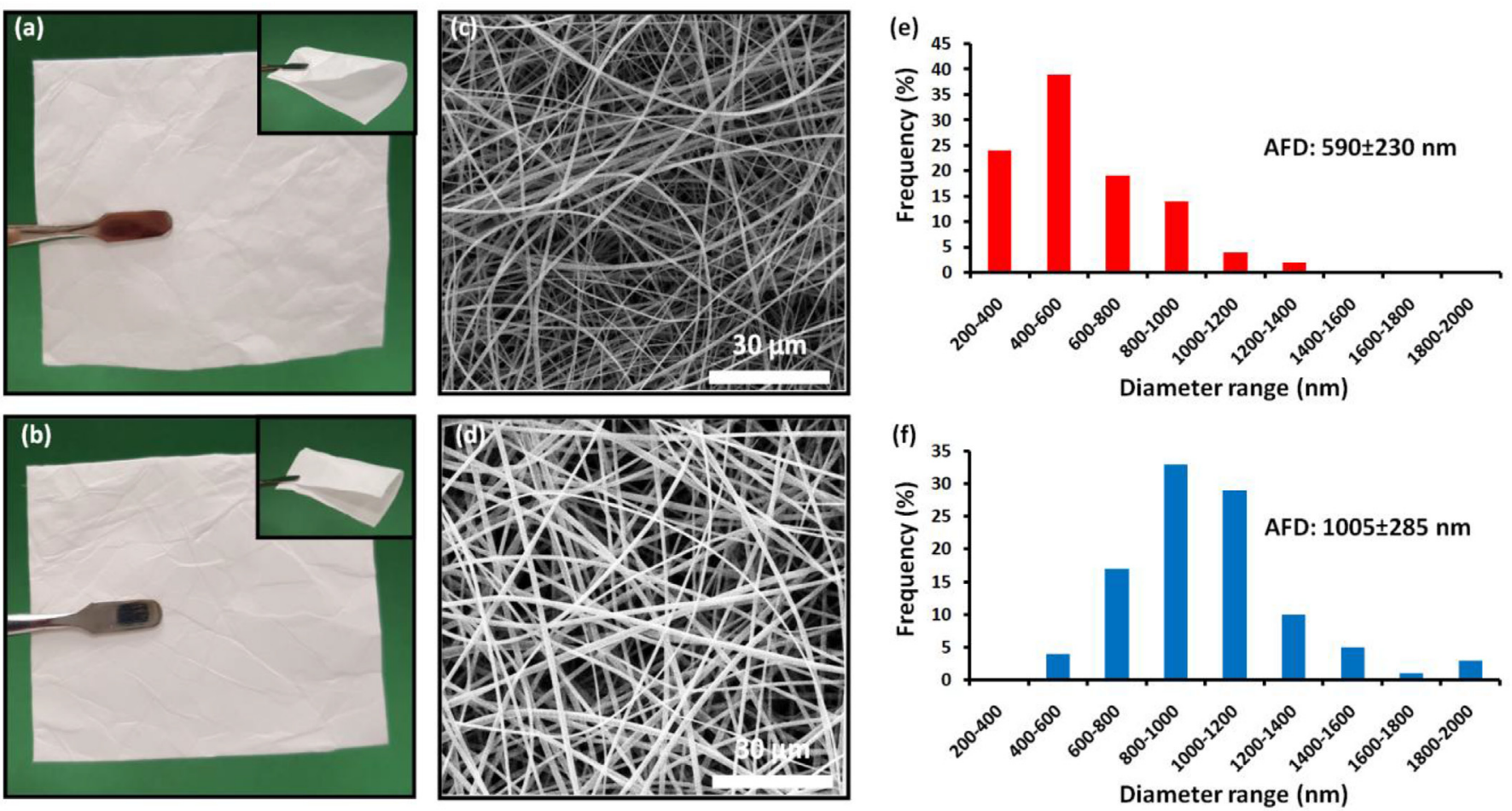

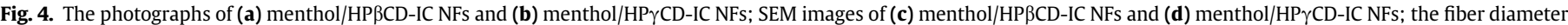
distribution with average fiber diameter (AFD) of (e) menthol/HP $\beta C D-I C$ NFs and (f) menthol/HP $\gamma$ CD-IC NFs.

Table 2

The properties of the solutions used for electrospinning and morphological characteristics of the resulting nanofibers.

\begin{tabular}{|c|c|c|c|c|c|}
\hline Solutions & Average fiber diameter (nm) & Fiber diameter range (nm) & Viscosity $(\mathrm{Pa} \cdot \mathrm{s})$ & Conductivity $(\mu \mathrm{S} / \mathrm{cm})$ & Morphology \\
\hline Menthol/HP $\beta C D-I C(1: 1)$ & $590 \pm 230$ & $210-1375$ & $0.200 \pm 0.017$ & $14.63 \pm 1.42$ & Bead-free nanofibers \\
\hline Menthol/HP $\gamma \mathrm{CD}-\mathrm{IC}(1: 1)$ & $1005 \pm 285$ & $470-1905$ & $0.300 \pm 0.015$ & $5.42 \pm 0.10$ & Bead-free nanofibers \\
\hline
\end{tabular}




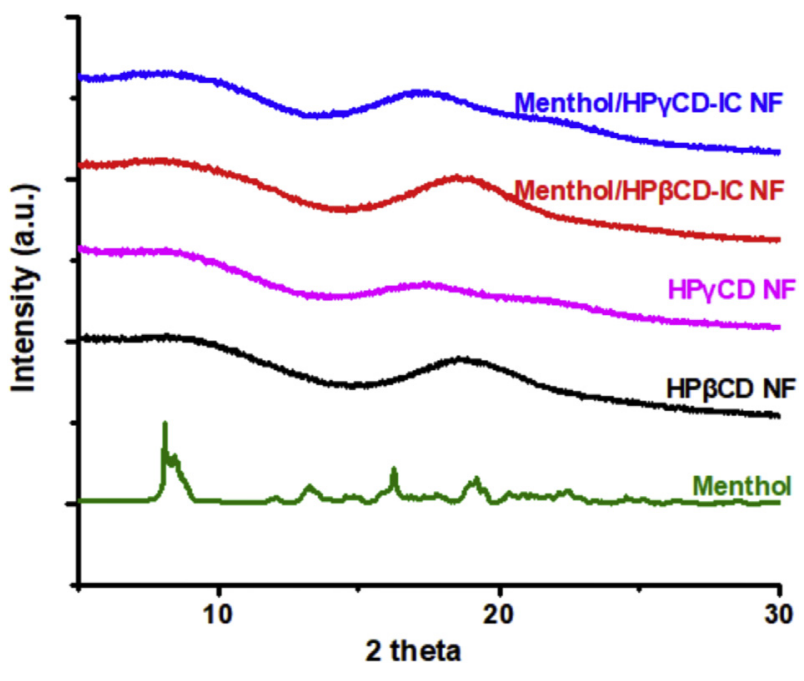

Fig. 6. XRD patterns of pure menthol, pure CD NFs and menthol/CD-IC NFs.

powder (approximately the same amount found in menthol/CD-IC NFs) and the menthol/CD-IC NFs samples were placed into petri dishes separately and then, $5 \mathrm{~mL}$ of water was added to these petri dishes.

Supplementary video related to this article can be found at https://doi.org/10.1016/j.jfoodeng.2017.12.020.

\section{Results and discussion}

\subsection{Phase solubility studies}

Phase solubility profiles of menthol/HP $\beta C D-I C$ and menthol/ $\mathrm{HP} \gamma \mathrm{CD}$-IC are given in Fig. 2. The diagram of profiles corresponds to the $A_{L}$ type in which the menthol concentration increased linearly by increasing $C D$ concentration which confirmed the increment in solubility by inclusion complexation. Moreover, this linear trend was the indication of $1: 1 \mathrm{M}$ ratio inclusion complex formation tendency between menthol and $\mathrm{CD}$ molecules.

Stability constant $\left(K_{s}\right)$ values for menthol/HP $\beta C D-I C$ and menthol/HP $\gamma$ CD-IC were calculated to represent the binding strength between menthol and $\mathrm{CDs}$. $\mathrm{K}_{\mathrm{s}}$ values were calculated as $716 \mathrm{M}^{-1}$ and $894 \mathrm{M}^{-1}\left(\mathrm{R}^{2}>0.99\right)$ for menthol/HP $\beta C D-I C$ and for menthol/HP $\gamma$ CD-IC, respectively, which demonstrated that menthol forms stable complexes with both CD types (HP $\beta C D$ and $\mathrm{HP} \gamma(\mathrm{CD})$ with similar stabilities.

\subsection{Molecular modeling for menthol/CD-IC}

The interaction of menthol and $\mathrm{CD}$ was examined at various sites for 1:1 stoichiometry and the lowest energy configurations for two vertical orientations of menthol (tail: the methyl group on the front, head: two methyl groups on the front) are illustrated in Fig. 3. Our calculations suggested that menthol prefers head and tail orientation for HP $\beta C D$ and $\mathrm{HP} \gamma \mathrm{CD}$, respectively. In both cases, polar hydroxyl group of menthol remained inside the cavity and menthol was shifted towards the sides to enhance the interaction. Cavity of $\mathrm{HP} \beta C D$ and $\mathrm{HP} \gamma \mathrm{CD}$ is large enough to accommodate menthol in lateral orientation; however, the structure was deformed for $\mathrm{HP} \beta C D$ whereas lateral orientation was possible for $\mathrm{HP} \gamma \mathrm{CD}$ without deformation. The calculations were repeated in water for the most favorable geometries and similar structural pattern was obtained, only the complexation energies ( $\left.\mathrm{E}_{\mathrm{comp}}\right)$ changed. The results are summarized in Table 1.
Positive and high $\mathrm{E}_{\mathrm{comp}}$ for all cases indicates stable IC formation between menthol and both $\mathrm{CD}$ types which was also confirmed by our phase solubility studies. For menthol/HP $\beta C D$-IC, the highest $\mathrm{E}_{\text {comp }}$ was obtained with head orientation in parallel with size matching while for menthol/HPrCD-IC, the highest $\mathrm{E}_{\text {comp }}$ was obtained with tail orientation (Table 1 ). On the other hand, for both of the $\mathrm{CDs}, \mathrm{E}_{\mathrm{comp}}$ decreased in water. Being menthol a polar molecule, the decrease in $\mathrm{E}_{\text {comp }}$ can be attributed to polar-polar interaction of guest molecule and the solvent. As discussed above, menthol can also laterally fit into cavity of $\mathrm{CD}$ and $\mathrm{E}_{\mathrm{comp}}$ was calculated as 21.25 and $23.19 \mathrm{kcal} / \mathrm{mol}$ in vacuum for $\mathrm{HP} \beta C D$ and $\mathrm{HP} \gamma \mathrm{CD}$, respectively. This indicated that interaction of menthol was stronger in lateral orientation for $\mathrm{HP} \gamma \mathrm{CD}$ when compared to HP $\beta C D$. The energy for $\mathrm{HP} \gamma \mathrm{CD}-\mathrm{IC}$ in lateral orientation was comparable with the energy in vertical orientation, suggesting the possibility of complexation in lateral orientation, as well.

The results for $\mathrm{E}_{\text {solv }}$ of menthol, $\mathrm{CDs}$ and their IC are given in Table 1 . $\mathrm{E}_{\text {solv }}$ of menthol was calculated as $-2.89 \mathrm{kcal} / \mathrm{mol}$ indicating a low solubility in water which is in agreement with the literature (Phunpee et al., 2016). However, $\mathrm{E}_{\text {solv }}$ values were high for both inclusion complexes, suggesting a substantial increase in solubility upon complexation and the higher $\mathrm{E}_{\text {solv }}$ was obtained for menthol/HP $\gamma \mathrm{CD}-\mathrm{IC}(-79.23 \mathrm{kcal} / \mathrm{mol})$ when compared to menthol/ HP $\beta C D-I C(-68.93 \mathrm{kcal} / \mathrm{mol})$.

\subsection{Morphological analyses of nanofibers}

The parameters of electrospinning process were optimized for the formation of the bead-free and uniform nanofibers. Highly concentrated (160\% CD, w/v) menthol/HP $\beta C D-I C$ and menthol/ $\mathrm{HP} \gamma \mathrm{CD}-\mathrm{IC}$ solutions were used for the electrospinning of nanofibers. The pictures of obtained electrospun nanofibrous webs are shown in Fig. 4a-b with their representative SEM images (Fig. 4c-d). The average fiber diameter (AFD) was $590 \pm 230 \mathrm{~nm}$ for menthol/HP $\beta C D-I C$ NFs and $1005 \pm 285 \mathrm{~nm}$ for menthol/HP $\gamma$ CD-IC NFs (Table 2). The viscosity of menthol/HPrCD-IC solution was higher than menthol/HP $\beta C D$-IC solution and the solution conductivity of menthol/HP $\gamma$ CD-IC was lower than menthol/HP $\beta C D-I C$. Hence, the higher AFD of menthol/HP $\gamma$ CD-IC NF was due to its higher solution viscosity and lower solution conductivity (Table 2) since its well-known that higher solution viscosity and lower solution conductivity results in less stretching of the electrified jet that forms thicker fibers during electrospinning process (Ramakrishna, 2005; Uyar and Besenbacher, 2008).

\subsection{Structural characterizations of nanofibers}

The detailed characterizations of menthol/CD-IC NFs were done by using FTIR and XRD. These characterizations were also performed for pure menthol and pure CD NFs for comparison. The FTIR spectra of pure menthol, pure CD nanofibers, and menthol/CD-IC NFs are shown in Fig. 5. The characteristic absorption bands of modified CDs are observed at around $3400 \mathrm{~cm}^{-1}(\mathrm{O}-\mathrm{H}$ stretching vibrations), $2932 \mathrm{~cm}^{-1}$ (C-H stretching vibrations), $1649 \mathrm{~cm}^{-1}(\mathrm{H}-$ $\mathrm{O}-\mathrm{H}$ bending vibrations) (Lu et al., 2014), $1155 \mathrm{~cm}^{-1}$ (asymmetric stretching vibration of C-O-C glycosidic bridge) 1032 and $1083 \mathrm{~cm}^{-1}$ (C-C, C-O stretching vibrations) (Kayaci and Uyar, 2011). The pure menthol spectrum showed the signature peaks at $3315 \mathrm{~cm}^{-1}$ (O-H stretching vibrations), $2850-2957 \mathrm{~cm}^{-1}$ (C-H stretching vibrations), $1025-1045 \mathrm{~cm}^{-1}$ (C-O stretching vibrations) (Phunpee et al., 2016) and $1367 \mathrm{~cm}^{-1}$ corresponding to isopropyl group (Al-Bayati, 2009). The overlapping of absorption peaks for menthol and CD molecules made the identification of each compounds complicated for menthol/CD-IC NFs samples. Yet, the sharpest absorption peak of menthol at about $1367 \mathrm{~cm}^{-1}$ was 
(a)

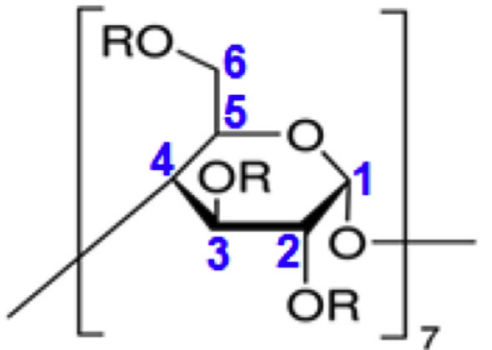

R: $\mathrm{CH}_{2} \mathrm{CHCH}_{3} \mathrm{OH}$

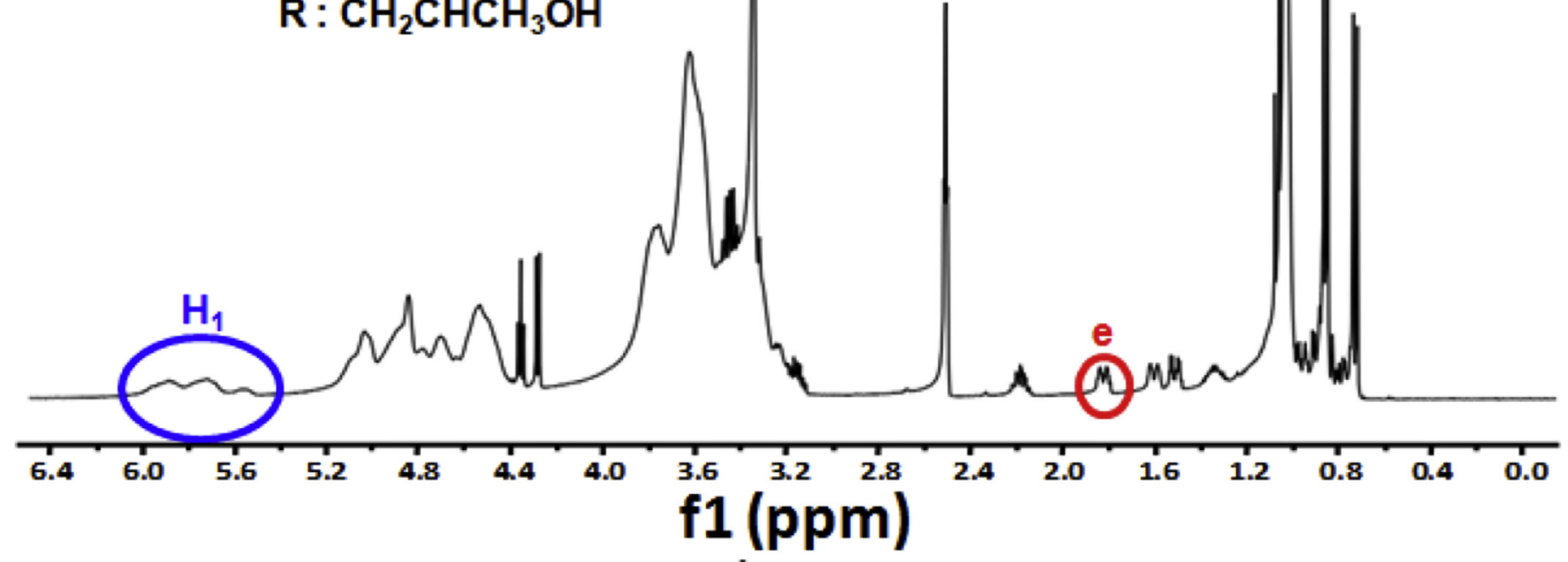

(b)

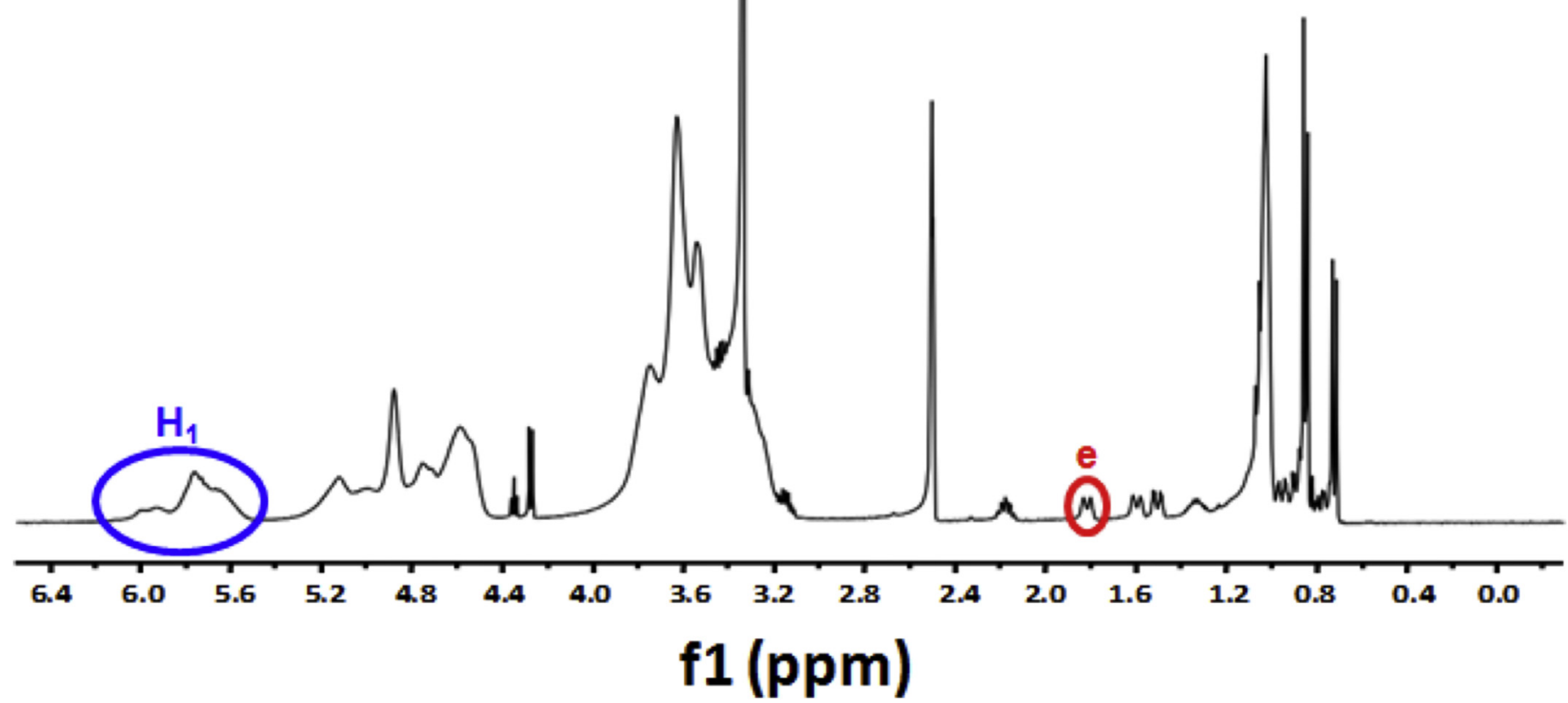

Fig. 7. ${ }^{1} \mathrm{H}$ NMR spectra of (a) menthol/HP $\beta C D-I C$ NFs and (b) menthol/HP $\gamma C D-I C$ NFs dissolved in DMSO-d6.

present at the FTIR spectra of menthol/CD-IC NFs samples whereas this peak was absent for the pure CD NFs samples. (Fig. 5). This suggested the presence of menthol in menthol/HPßCD-IC NF and menthol/HP $\gamma$ CD-IC NF samples.

The crystalline structures of menthol, pure CD NFs and menthol/ CD-IC NFs were investigated by XRD. The XRD patterns of menthol/
CD-IC NFs webs were very similar to those of pure CD NFs webs having amorphous structure (Fig. 6). Besides, they did not show any diffraction peaks of menthol suggesting that menthol molecules were possibly isolated from each other by entering into CD cavities and cannot form any crystalline aggregates (Celebioglu and Uyar, 2011, 2012, 2013; Kayaci et al., 2013; Kayaci and Uyar, 2011). In 


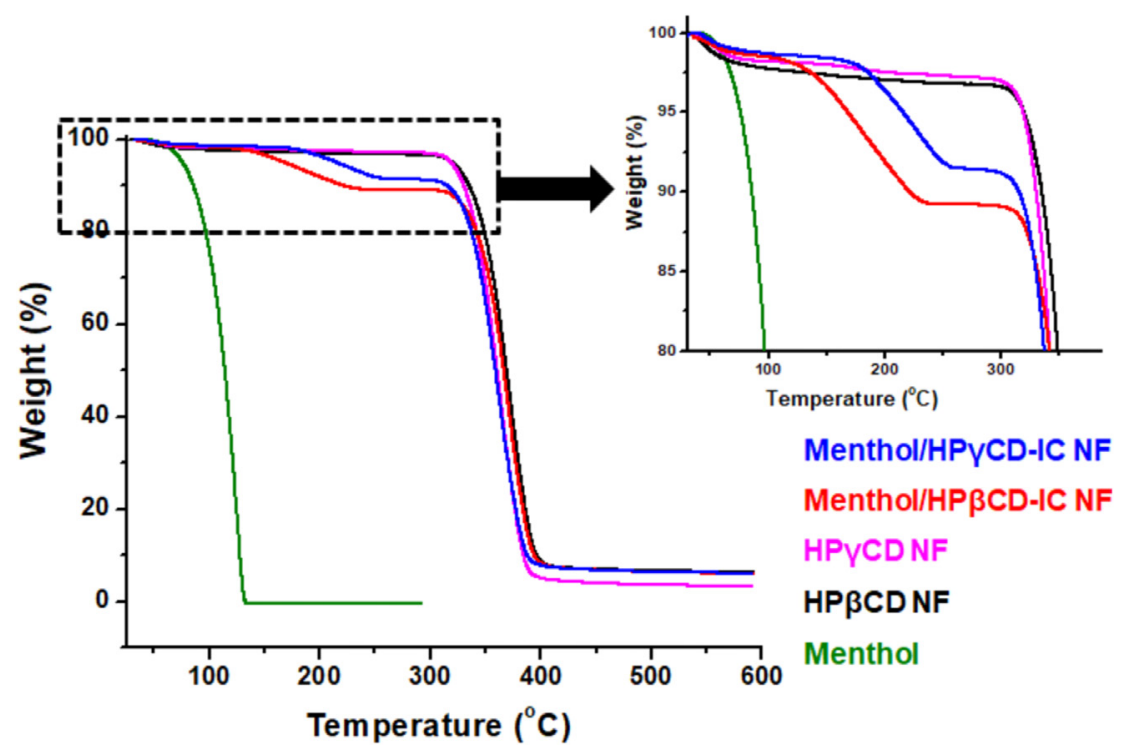

Fig. 8. TGA thermogram of pure menthol, pure CD NFs and menthol/CD-IC NFs.

other words, XRD results suggested the IC formation between CD and menthol molecules in menthol/HP $\beta C D-I C$ NFs and menthol/ $\mathrm{HP} \gamma \mathrm{CD}-\mathrm{IC}$ NFs samples.

\subsection{The molar ratio in menthol/CD-IC NFs}

${ }^{1} \mathrm{H}$ NMR study was performed to validate the presence of menthol and to determine the molar ratio between menthol and CD in menthol/CD-IC NFs by dissolving the samples in DMSO-d6. Initially, a ${ }^{1} \mathrm{H}$ NMR study was performed to detect the characteristic peaks corresponding to protons of CD NFs and pure menthol. The characteristic peaks of menthol were observed in the ${ }^{1} \mathrm{H}$ NMR spectra of menthol/CD-IC NFs which confirmed the presence of menthol in the menthol/CD-IC NFs samples. The molar ratios were calculated by taking integration of menthol peak at around $1.85 \mathrm{ppm}$ (H-e) and the CD peak at around $5.8 \mathrm{ppm}$ (H-1) (Fig. 7). It was calculated that the molar ratio of menthol to HP $\beta C D$ and $\mathrm{HP} \gamma \mathrm{CD}$ was $\sim 0.75: 1.00$ and $\sim 0.70: 1.00$ in menthol/HP $\beta C D-I C$ NFs

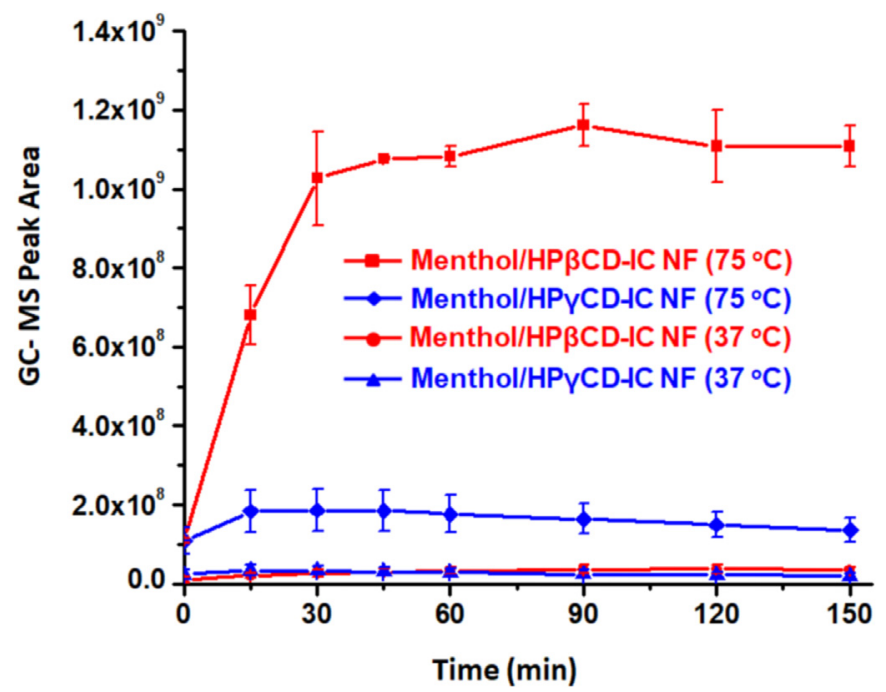

Fig. 9. The cumulative release of menthol from menthol/HP $\beta C D-I C$ NFs and menthol/ $\mathrm{HP} \gamma \mathrm{CD}-\mathrm{IC}$ NFs at $37^{\circ} \mathrm{C}$ and $75^{\circ} \mathrm{C},(\mathrm{n}=3)$. and menthol/HP $\gamma$ CD-IC NFs samples, respectively. The molar ratio found for menthol/CD-IC NFs samples was lower than the initial ratio (1.00:1.00) and this is probably because of some uncomplexed menthol in menthol/CD-IC systems; however, menthol was mostly preserved during electrospinning process and/or during storage. ${ }^{1} \mathrm{H}$ NMR results revealed that menthol/HP $\beta C D-I C$ NFs shows a slightly higher molar ratio which means higher complexation efficiency than menthol/HP $\gamma$ CD-IC NFs. Encapsulation efficiency (EE\%) of menthol for menthol/CD-IC NFs was also calculated from the results of ${ }^{1} \mathrm{H}$ NMR. EE\% was found as $75 \%$ for menthol/HP $\beta C D-I C$ and $\sim 70 \%$ for menthol/HP $\gamma$ CD-IC NFs.

\subsection{Thermal characterization of nanofibers}

The thermal properties and thermal stability of menthol in menthol/CD-IC NFs were investigated by TGA. The TGA studies of pure CD NFs and pure menthol were also performed for comparison. The TGA thermograms of pure CD NFs have two weight losses (Fig. 8). The first one is below $100^{\circ} \mathrm{C}$ corresponding to water losses and the second one is above $300^{\circ} \mathrm{C}$ corresponding to main degradation of $\mathrm{CD}$ molecules. The TGA thermogram of pure menthol has one major weight loss due to its evaporation in the range of $50-130^{\circ} \mathrm{C}$ indicating its highly volatile nature. For menthol/CD-IC $\mathrm{NFs}$, the water loss below $100^{\circ} \mathrm{C}$ and the $\mathrm{CD}$ degradation above $300^{\circ} \mathrm{C}$ were also observed. Beside these losses, there was weight loss between $110-220^{\circ} \mathrm{C}$ and $150-275^{\circ} \mathrm{C}$ for menthol/HP $\beta C D-I C$ $\mathrm{NFs}$ and menthol/HP $\gamma \mathrm{CD}-\mathrm{IC}$ NFs, respectively, which belong to evaporation of menthol. The evaporation of menthol was shifted from 50 to $130^{\circ} \mathrm{C}$ to much higher temperature $\left(110-220^{\circ} \mathrm{C}\right.$ and $150-275^{\circ} \mathrm{C}$ ) for menthol/CD-IC NFs which proved the presence of inclusion complexation between $\mathrm{CD}$ and menthol for both menthol/CD-IC NFs samples. TGA data clearly showed that thermal stability of menthol was enhanced significantly for menthol/CD-IC NFs due to IC formation (Celebioglu et al., 2014). From TGA thermogram, the amount of menthol in the menthol/HP $\beta C D-I C$ NFs was calculated as $9.3 \%(\mathrm{w} / \mathrm{w}$, with respect to HP $\beta C D$ ) that refers to the $\sim 0.90: 1.00 \mathrm{M}$ ratio complexation. On the other hand, menthol amount in the menthol/HP $\gamma$ CD-IC NFs was calculated as $7.0 \%(\mathrm{w} / \mathrm{w}$, with respect to $\mathrm{HP} \gamma \mathrm{CD}$ ) that refers to $\sim 0.75: 1.00 \mathrm{M}$ ratio complexation. TGA data indicated that significant amount of menthol was preserved and protected against evaporation during 


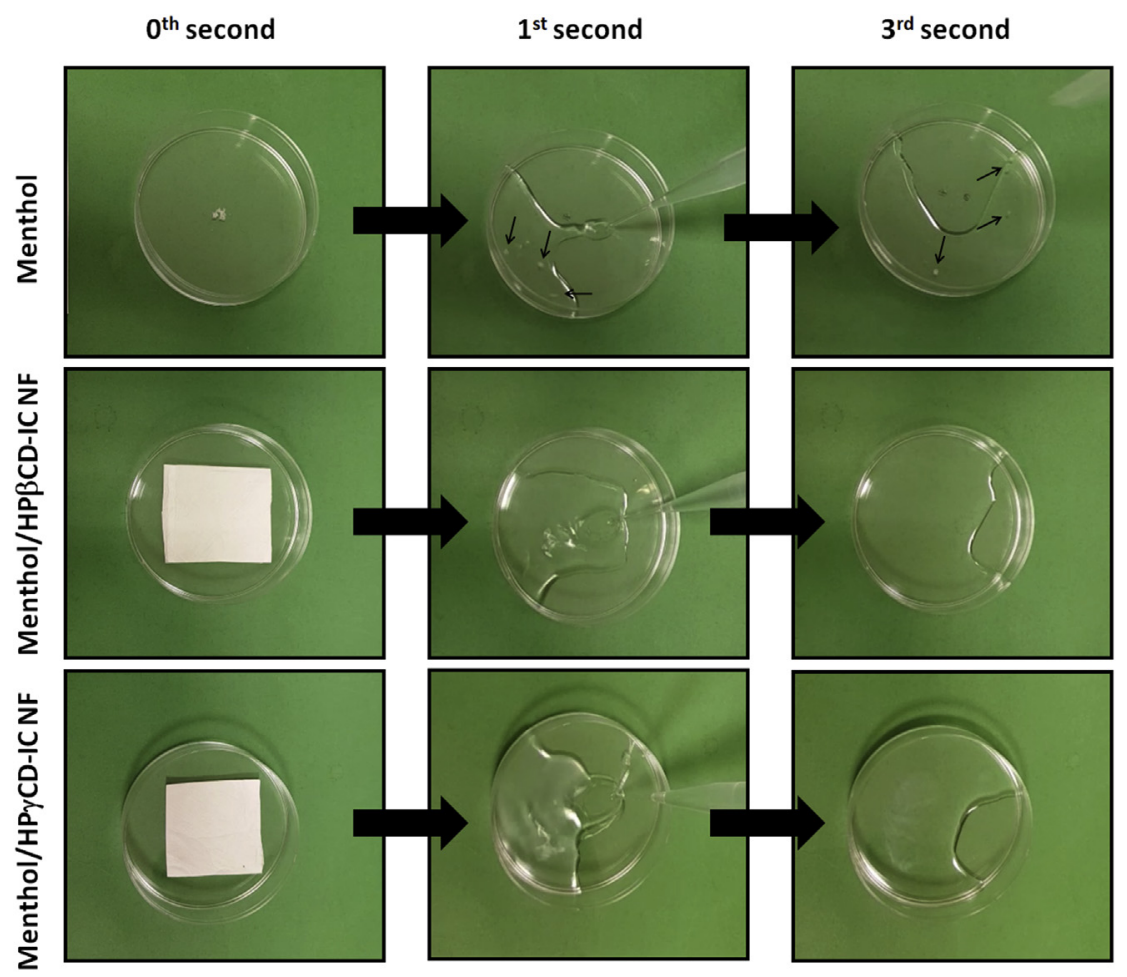

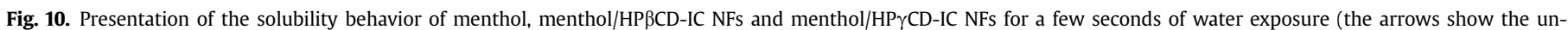
dissolved menthol crystals). The pictures were captured from the video which was given as Supplementary information.

electrospinning process and storage for menthol/CD-IC NFs samples. Although the calculated amount of menthol from TGA in menthol/CD-IC NFs was not exactly same with the menthol amount calculated from ${ }^{1} \mathrm{H}$ NMR analyses, both results were comparable and consistent with each other suggesting that highly volatile menthol was successfully preserved in menthol/CD-IC NFs samples due to inclusion complexation.

\subsection{Release studies of menthol from menthol/CD-IC NFs}

The high volatility of menthol is very important problem for its shelf-life and applications, therefore; temperature stability and slow release of menthol is very crucial. The release profile of menthol/CD-IC NFs obtained from HS GC-MS are given in Fig. 9. The higher amount of menthol released at higher temperature due to uncomplexation of menthol from the CD cavity (Yang et al., 2015). The TGA and ${ }^{1} \mathrm{H}$ NMR results showed that menthol/HP $\beta C D-I C$ NFs has higher amount of menthol and therefore higher amount of menthol released from menthol/HP $\beta C D-I C$ NFs at both applied temperatures (at $37^{\circ} \mathrm{C}$ and at $75^{\circ} \mathrm{C}$ ) as compared to menthol/ HP $\gamma$ CD-IC NFs. Moreover, after certain time, the release of menthol has become slower for both menthol/CD-IC NFs samples. In other words, the slow-release of menthol was achieved thanks to inclusion complex formation which could lead to shelf-life improvement of menthol for menthol/CD-IC NF samples.

\subsection{Fast-dissolving character of menthol/CD-IC NFs}

The fast-dissolving property and water-solubility enhancement of the menthol for menthol/CD-IC NFs was visually studied (Video $\mathrm{S} 1$ and Fig. 10). The addition of water to petri dishes dissolved both menthol/CD-IC NFs within $1 \mathrm{~s}$ while pure menthol remained undissolved. This proved that menthol/CD-IC NFs has fast-dissolving character and provides water-solubility enhancement of menthol.

\section{Conclusion}

In this study, the fabrication of free-standing nanofibrous webs from menthol/cyclodextrin-inclusion complex (menthol/CD-IC) by using the electrospinning technique without using a carrier polymer matrix was presented. Two modified CDs (HP $\beta C D$ and HP $\gamma C D$ ) were used and the menthol/CD-IC NFs were electrospun from highly concentrated aqueous solutions of menthol/CD-IC. The fastdissolving menthol/CD-IC NFs have combined advantages of cyclodextrin inclusion complexation and high surface area of electrospun nanofibers. The menthol/CD-IC NFs have shown improvement for menthol such as enhancement in water-solubility, increase in thermal stability, and slow release of menthol. In brief, encapsulation of menthol in electrospun polymer-free CD-IC NF matrix may have potentials for food, oral-care and pharmaceuticals applications.

\section{Acknowledgement}

Dr. Uyar acknowledges The Scientific and Technological Research Council of Turkey (TUBITAK)-Turkey (Project \# 213M185) for funding this research. Z. I. Yildiz thank to TUBITAK-BIDEB for the PhD scholarship.

\section{References}

Ades, H., Kesselman, E., Ungar, Y., Shimoni, E., 2012. Complexation with starch for encapsulation and controlled release of menthone and menthol. Lwt-Food Sci. Technol. 45 (2), 277-288.

Al-Bayati, FA., 2009. Isolation and identification of antimicrobial compound from Mentha longifolia L. leaves grown wild in Iraq. Ann. Clin. Microbiol. Antimicrob. $8,20$.

Aytac, Z., Keskin, N.O.S., Tekinay, T., Uyar, T., 2017a. Antioxidant alpha-tocopherol/ gamma-cyclodextrin-inclusion complex encapsulated poly(lactic acid) electrospun nanofibrous web for food packaging. J. Appl. Polym. Sci. 134 (21), 44858. Aytac, Z., Yildiz, Z.I., Kayaci-Senirmak, F., Keskin, N.O.S., Kusku, S.I., Durgun, E., 
Tekinay, T., Uyar, T., 2016a. Fast-dissolving, prolonged release, and antibacterial cyclodextrin/limonene-inclusion complex nanofibrous webs via polymer-free electrospinning. J. Agric. Food Chem. 64 (39), 7325-7334.

Aytac, Z., Yildiz, Z.I., Kayaci-Senirmak, F., Keskin, N.O.S., Tekinay, T., Uyar, T., 2016b. Electrospinning of polymer-free cyclodextrin/geraniol-inclusion complex nanofibers: enhanced shelf-life of geraniol with antibacterial and antioxidant properties. Rsc Adv. 6 (52), 46089-46099.

Aytac, Z., Yildiz, Z.I., Kayaci-Senirmak, F., Tekinay, T., Uyar, T., 2017b. Electrospinning of cyclodextrin/linalool-inclusion complex nanofibers: fast-dissolving nanofibrous web with prolonged release and antibacterial activity. Food Chem. 231, 192-201.

Blochl, P.E., 1994. Projector augmented-wave method. Phys. Rev. B 50 (24), 17953-17979.

Buschmann, H.J., Schollmeyer, E., 2002. Applications of cyclodextrins in cosmetic products: a review. J. Cosmet. Sci. 53 (3), 185-191.

Celebioglu, A., Kayaci-Senirmak, F., Ipek, S., Durgun, E., Uyar, T., 2016. Polymer-free nanofibers from vanillin/cyclodextrin inclusion complexes: high thermal stability, enhanced solubility and antioxidant property. Food Funct. 7 (7), $3141-3153$.

Celebioglu, A., Umu, O.C.O., Tekinay, T., Uyar, T., 2014. Antibacterial electrospun nanofibers from triclosan/cyclodextrin inclusion complexes. Colloids Surfaces B Biointerfaces 116, 612-619.

Celebioglu, A., Uyar, T., 2011. Electrospinning of polymer-free nanofibers from cyclodextrin inclusion complexes. Langmuir 27 (10), 6218-6226.

Celebioglu, A., Uyar, T., 2012. Electrospinning of nanofibers from non-polymeric systems: polymer-free nanofibers from cyclodextrin derivatives. Nanoscale 4 (2), 621-631.

Celebioglu, A., Uyar, T., 2013. Electrospinning of nanofibers from non-polymeric systems: electrospun nanofibers from native cyclodextrins. J. Colloid Interface Sci. 404, 1-7.

Celebioglu, A., Uyar, T., 2017. Antioxidant vitamin e/cyclodextrin inclusion complex electrospun nanofibers: enhanced water solubility, prolonged shelf life, and photostability of vitamin E. J. Agric. Food Chem. 65 (26), 5404-5412.

Del Valle, E.M.M., 2004. Cyclodextrins and their uses: a review. Process Biochem. 39 (9), 1033-1046.

Galeotti, N., Mannelli, L.D., Mazzanti, G., Bartolini, A., Ghelardini, C., 2002. Menthol: a natural analgesic compound. Neurosci. Lett. 322 (3), 145-148.

Grimme, S., 2006. Semiempirical GGA-type density functional constructed with a long-range dispersion correction. J. Comput. Chem. 27 (15), 1787-1799.

Hedges, A.R., 1998. Industrial applications of cyclodextrins. Chem. Rev. 98 (5), 2035-2044.

Higuchi, T., Connors, A., 1965. Phase solubility techniques. Adv. Anal. Chem. Instrum. 4, 117-212.

Hohenberg, P., Kohn, W., 1964. Inhomogeneous electron gas. Phys. Rev. 136 (3B), B864.

Kayaci, F., Umu, O.C., Tekinay, T., Uyar, T., 2013. Antibacterial electrospun poly(lactic acid) (PLA) nanofibrous webs incorporating triclosan/cyclodextrin inclusion complexes. J. Agric. Food Chem. 61 (16), 3901-3908.

Kayaci, F., Uyar, T., 2011. Solid inclusion complexes of vanillin with cyclodextrins: their formation, characterization, and high-temperature stability. J. Agric. Food Chem. 59 (21), 11772-11778.

Kohn, W., Sham, L.J., 1965. Self-consistent equations including exchange and correlation effects. Phys. Rev. 140 (4A), A1133.

Kresse, G., Furthmuller, J., 1996. Efficient iterative schemes for ab initio total-energy calculations using a plane-wave basis set. Phys. Rev. B 54 (16), 11169-11186.
Liu, X.D., Furuta, T., Yoshii, H., Linko, P., Coumans, W.J., 2000. Cyclodextrin encapsulation to prevent the loss of l-menthol and its retention during drying. Biosci. Biotechnol. Biochem. 64 (8), 1608-1613.

Lu, Y.P., Liu, S.Y., Zhao, Y., Zhu, L., Yu, S.Q., 2014. Complexation of Z-ligustilide with hydroxypropyl-beta-cyclodextrin to improve stability and oral bioavailability. Acta Pharm. 64 (2), 211-222.

Marques, H.M.C., 2010. A review on cyclodextrin encapsulation of essential oils and volatiles. Flavour Fragrance J. 25 (5), 313-326.

Mathew, K., Sundararaman, R., Letchworth-Weaver, K., Arias, T.A., Hennig, R.G., 2014. Implicit solvation model for density-functional study of nanocrystal surfaces and reaction pathways. J. Chem. Phys. 140 (8), 084106.

Noruzi, M., 2016. Electrospun nanofibres in agriculture and the food industry: a review. J. Sci. Food Agric. 96 (14), 4663-4678.

Patel, T., Ishiuji, Y., Yosipovitch, G., 2007. Menthol: a refreshing look at this ancient compound. J. Am. Acad. Dermatol. 57 (5), 873-878.

Perdew, J.P., Burke, K., Ernzerhof, M., 1996. Generalized gradient approximation made simple. Phys. Rev. Lett. 77 (18), 3865-3868.

Phunpee, S., Saesoo, S., Sramala, I., Jarussophon, S., Sajomsang, W. Puttipipatkhajorn, S., Soottitantawat, A., Ruktanonchai, U.R., 2016. A comparison of eugenol and menthol on encapsulation characteristics with water-soluble quaternized beta-cyclodextrin grafted chitosan. Int. J. Biol. Macromol. 84, $472-480$.

Ramakrishna, S., 2005. An Introduction to Electrospinning and Nanofibers. World Scientific, Hackensack, NJ.

Sahay, R., Kumar, P.S., Sridhar, R., Sundaramurthy, J., Venugopal, J., Mhaisalkar, S.G. Ramakrishna, S., 2012. Electrospun composite nanofibers and their multifaceted applications. J. Mater. Chem. 22 (26), 12953-12971.

Shenoy, S.L., Bates, W.D., Frisch, H.L., Wnek, G.E., 2005. Role of chain entanglements on fiber formation during electrospinning of polymer solutions: good solvent non-specific polymer-polymer interaction limit. Polymer 46 (10), 3372-3384.

Szejtli, J., 1998. Introduction and general overview of cyclodextrin chemistry. Chem. Rev. 98 (5), 1743-1753.

Theron, S.A., Zussman, E., Yarin, A.L., 2004. Experimental investigation of the governing parameters in the electrospinning of polymer solutions. Polymer 45 (6) 2017-2030.

Uyar, T., Besenbacher, F., 2008. Electrospinning of uniform polystyrene fibers: the effect of solvent conductivity. Polymer 49 (24), 5336-5343.

Uyar, T., Hacaloglu, J., Besenbacher, F., 2009a. Electrospun polystyrene fibers containing high temperature stable volatile fragrance/flavor facilitated by cyclodextrin inclusion complexes. React. Funct. Polym. 69 (3), 145-150.

Uyar, T., Hacaloglu, J., Besenbacher, F., 2011. Electrospun polyethylene oxide (PEO) nanofibers containing cyclodextrin inclusion complex. J. Nanosci. Nanotechnol. 11 (5), 3949-3958.

Uyar, T., Kny, E., 2017. Electrospun Materials for Tissue Engineering and Biomedical Applications. Woodhead Publishing.

Uyar, T., Nur, Y., Hacaloglu, J., Besenbacher, F., 2009b. Electrospinning of functional poly(methyl methacrylate) nanofibers containing cyclodextrin-menthol inclusion complexes. Nanotechnology 20 (12), 125703.

Yang, Z.J., Xiao, Z.B., Ji, H.B., 2015. Solid inclusion complex of terpinen-4-ol/betacyclodextrin: kinetic release, mechanism and its antibacterial activity. Flavour Fragrance J. 30 (2), 179-187.

Zhu, G.Y., Xiao, Z.B., Zhu, G.X., Rujunzhou, Niu, Y.W., 2016. Encapsulation of 1menthol in hydroxypropyl-beta-cyclodextrin and release characteristics of the inclusion complex. Pol. J. Chem. Technol. 18 (3), 110-116. 